Heat transfer and entropy generation of mixed convection in nanofluid inside a rough cavity

Kevin Ting, Aloke K. Mozumder, and Prodip K. Das

Citation: AIP Conference Proceedings 1980, 050005 (2018); doi: 10.1063/1.5044341

View online: https://doi.org/10.1063/1.5044341

View Table of Contents: http://aip.scitation.org/toc/apc/1980/1

Published by the American Institute of Physics 


\title{
Heat Transfer and Entropy Generation of Mixed Convection in Nanofluid inside a Rough Cavity
}

\author{
Kevin Ting ${ }^{1}$, Aloke K. Mozumder ${ }^{2}$, and Prodip K. Das ${ }^{1, \text { a) }}$ \\ ${ }^{I}$ School of Engineering,Newcastle University, Newcastle upon Tyne, NE1 7RU, United Kingdom \\ ${ }^{2}$ Department of Mechanical Engineering, Bangladesh University of Engineering and Technology, Dhaka, \\ Bangladesh \\ ${ }^{a)}$ Corresponding author: prodip.das@ncl.ac.uk
}

\begin{abstract}
A two-dimensional numerical model has been developed to investigate the mixed convection heat transfer and entropy generation of $\mathrm{Al}_{2} \mathrm{O}_{3}$-water nanofluid inside a rough cavity. The numerical model is developed using commercial finite volume software ANSYS-FLUENT inside a square cavity with various roughness elements. Here the vertical walls of the cavity are adiabatic, horizontal walls are maintained at constant temperatures, and the top wall is moving at a constant velocity. The rough bottom wall is maintained at a higher temperature, where the roughness elements are introduced by making the surface wavy. The effects of elements number and amplitude of the roughness elements on the heat transfer, fluid flow, and entropy generation are analyzed. The flow fields, temperature fields, and heat transfer rates are examined for different values of Reynolds numbers, while the entropy generation is characterized by the Bejan number, heat transfer irreversibility, and fluid friction irreversibility. The outcome of this study provides some important insight into the heat transfer behavior due to the surface roughness, which could potentially be used in developing novel geometries with enhanced and controlled heat transfer for complex engineering applications.
\end{abstract}

\section{INTRODUCTION}

Convective heat transfer of conventional heat-transfer fluids (such as air, water or oil) in cavities (such as square, wavy, inclined, cylindrical annuli, or triangular) has long been a question of great interest in a wide range of fields [1-14]. Flow and heat transfer from such irregular surfaces are often encountered in many engineering applications such that it is in great need to enhance heat transfer in the cooling system of microelectronic devices, flat-plate solar collectors, flat plate condensers in the refrigerator and underground cable system, etc. However, conventional heattransfer fluids used in heat transfer applications have low thermal conductivity. Thus, there is a great need to develop new kind of fluids that are more effective in terms of heat transfer performances. Nanofluids are fluids containing metallic nanometer-sized particles suspended stably and uniformly in a base-fluid (such as water, ethylene glycol, etc.). The use of metallic nanoparticles in nanofluids results in higher thermal conductivities and heat transfer coefficients as compared to the base-fluid, making them more efficient for heat transfer applications. Although many experimental studies have been conducted for nanofluids showing their better thermal properties and thermal performances [15-17], it is not clear whether the enhancement of thermal conductivity would be beneficial for mixed convection in the confined cavities. Thus, there is a need to investigate mixed convection of nanofluids in enclosed spaces. In this study, a two-dimensional numerical model has been developed to investigate the mixed convection heat transfer and entropy generation of $\mathrm{Al}_{2} \mathrm{O}_{3}$-water nanofluid inside a rough cavity and to analyze the effects of elements number and amplitude of the roughness elements on heat transfer, fluid flow, and entropy generation. The flow fields, temperature fields, and heat transfer rates are examined for different values of Reynolds numbers, while the entropy generation is examined by the Bejan number, heat transfer irreversibility, and fluid friction irreversibility. 


\section{PROBLEM DESCRIPTION}

Figure 1 shows a schematic diagram of the two-dimensional lid-driven square cavity with roughness elements at the bottom wall. Here $H$ and $L$ are the height and length of the cavity. $A$ and $N$ are the scaled amplitude and the scaled number of roughness elements with respect to the cavity length and height, respectively. The top wall of the cavity is moving in the $x$-direction from left to right with a uniform velocity. The top wall is kept at a constant temperature $\left(T_{\min }\right)$, while the roughness elements have a higher wall temperature $\left(T_{\max }\right)$. The two vertical walls are considered to be adiabatic and non-slip condition is applied. The dimensionless velocity components $(U$ and $V)$ and temperature $(\Theta)$ in Figure 1 are expressed as:

$$
U=\frac{u}{u_{0}}, V=\frac{v}{u_{0}}, \Theta=\frac{T-T_{\min }}{T_{\max }-T_{\min }} \text {, and } \Delta T=T_{\max }-T_{\min }
$$

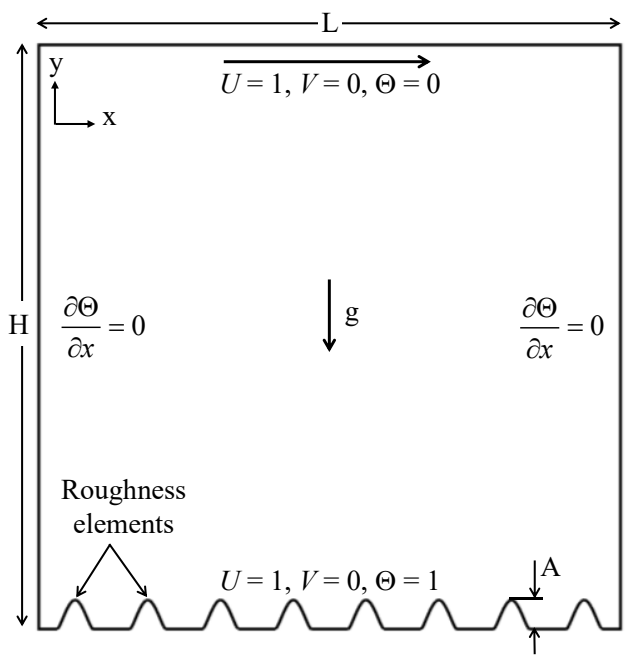

FIGURE 1. Schematic diagram of geometry with eight roughness elements.

Considering $\mathrm{Al}_{2} \mathrm{O}_{3}$-water nanofluids to be Newtonian, incompressible, and the flow inside the above cavity is laminar, the governing conservation equations of mass, momentum, and energy in a steady state, two-dimensional laminar and incompressible flow are used in this study along with the Boussinesq approximation in the $y$-direction, which are expressed as [18]:

$$
\begin{gathered}
\frac{\partial u}{\partial x}+\frac{\partial v}{\partial y}=0 \\
u \frac{\partial u}{\partial x}+v \frac{\partial u}{\partial y}=-\frac{1}{\rho_{n f}} \frac{\partial p}{\partial x}+\frac{\mu_{n f}}{\rho_{n f}}\left(\frac{\partial^{2} u}{\partial x^{2}}+\frac{\partial^{2} u}{\partial y^{2}}\right) \\
u \frac{\partial v}{\partial x}+v \frac{\partial v}{\partial y}=-\frac{1}{\rho_{n f}} \frac{\partial p}{\partial y}+\frac{\mu_{n f}}{\rho_{n f}}\left(\frac{\partial^{2} v}{\partial x^{2}}+\frac{\partial^{2} v}{\partial y^{2}}\right)+\frac{(\rho \beta)_{n f}}{\rho_{n f}} g\left(T-T_{\infty}\right) \\
u \frac{\partial T}{\partial x}+v \frac{\partial T}{\partial y}=\frac{k_{n f}}{\left(\rho C_{p}\right)_{n f}}\left(\frac{\partial^{2} T}{\partial x^{2}}+\frac{\partial^{2} T}{\partial y^{2}}\right)
\end{gathered}
$$

where $u, v, p$, and $T$ are the velocities, pressure, and temperature, respectively, and $\mu, \rho, \beta, k$, and $c_{p}$ are the dynamic viscosity, density, thermal expansion coefficient, thermal conductivity, and specific heat capacity, respectively. The subscript $n f$ represents the effective properties of nanofluid. The nanofluid effective properties are estimated using 
the effective medium theory as it provides a reasonable estimate of effective properties and this theory has been widely used for multiphase systems [19-24]. The following expressions are used for the nanofluid effective properties:

$$
\begin{gathered}
\rho_{n f}=(1-\varphi) \rho_{f}+\varphi \rho_{s} \\
\left(\rho C_{p}\right)_{n f}=(1-\varphi)\left(\rho C_{p}\right)_{f}+\varphi\left(\rho C_{p}\right)_{s} \\
(\rho \beta)_{n f}=(1-\varphi)(\rho \beta)_{f}+\varphi(\rho \beta)_{s} \\
\mu_{n f}=\frac{\mu_{f}}{(1-\varphi)^{2.5}} \\
k_{n f}=k_{f} \frac{k_{s}+2 k_{f}-2 \varphi\left(k_{f}-k_{s}\right)}{k_{s}+2 k_{f}+\varphi\left(k_{f}-k_{s}\right)}
\end{gathered}
$$

where the subscripts $f$ and $s$ denote water and $\mathrm{Al}_{2} \mathrm{O}_{3}$ nanoparticles, respectively. It is assumed that the shape and size of $\mathrm{Al}_{2} \mathrm{O}_{3}$ nanoparticles are uniform and in thermal equilibrium with the base fluid (water), and the radiative heat transfer and chemical reaction between water and $\mathrm{Al}_{2} \mathrm{O}_{3}$ nanoparticles, and viscous dissipation term in the heat transport equation are negligible. Thus, the thermophysical properties of $\mathrm{Al}_{2} \mathrm{O}_{3}$-water nanofluid are assumed to be constant except the density in buoyancy term. Thermophysical properties of water and $\mathrm{Al}_{2} \mathrm{O}_{3}$ nanoparticles used to evaluate the effective properties of $\mathrm{Al}_{2} \mathrm{O}_{3}$-water nanofluid for the numerical simulations are listed in Table 1 .

TABLE 1. Properties of water and $\mathrm{Al}_{2} \mathrm{O}_{3}$ nanoparticles [18].

\begin{tabular}{ccc}
\hline Variables & Water & $\begin{array}{c}\mathbf{A l}_{2} \mathbf{O}_{3} \\
\text { nanoparticles }\end{array}$ \\
\hline$C_{p}[\mathrm{~J} /(\mathrm{kg} \cdot \mathrm{K})]$ & 4179 & 765 \\
$\rho\left[\mathrm{kg} / \mathrm{m}^{3}\right]$ & 997.1 & 3970 \\
$k[\mathrm{~W} / \mathrm{m} \cdot \mathrm{K}]$ & 0.613 & 40 \\
$\beta[1 / \mathrm{K}]$ & $2.1 \times 10^{-4}$ & $8.5 \times 10^{-6}$ \\
$\mu[\mathrm{kg} / \mathrm{m}]$ & $1.002 \times 10^{-3}$ & - \\
\hline
\end{tabular}

\section{NUMERICAL MODELING}

The governing nonlinear partial differential equations are solved using the commercial finite volume based software, ANSYS-FLUENT. A second-order upwind scheme is used for the spatial discretization of the governing equations. The velocity-pressure coupling is done by the SIMPLE algorithm and the pressure based solver is used to compute the solution. The solution of the governing equations is considered converged when the residuals are smaller than $10^{-6}$ for the mass and momentum equations and smaller than $10^{-8}$ for the energy equation. The mesh independence test is performed by comparing numerical results for various meshes to ensure that the results are independent of mesh sizes. Once a converged solution is obtained, the average Nusselt number $\left(\mathrm{Nu}_{\mathrm{avg}}\right)$ is calculated through the integration of the local Nusselt number $\left(\mathrm{Nu}_{H}\right)$ over the roughness elements using the following expression

$$
\mathrm{Nu}_{\text {avg }}=\frac{1}{A} \int \mathrm{Nu}_{H} \cdot \mathrm{d} A
$$

Here area-weighted average value is taken as it divides the product of selected field variable and cell area by the surface area to give a dimensionless value. Finally, the total entropy generation associated with the heat transfer and 
fluid friction is calculated using the formulation suggested by Bejan [25]. The expression of the total entropy generation is expressed as $[11,25]$ :

$$
s_{\text {gen }}=\frac{k_{n f}}{T_{0}^{2}}\left[\left(\frac{\partial T}{\partial x}\right)^{2}+\left(\frac{\partial T}{\partial y}\right)^{2}\right]+\frac{\mu_{n f}}{T_{0}}\left[2\left\{\left(\frac{\partial u}{\partial x}\right)^{2}+\left(\frac{\partial v}{\partial y}\right)^{2}\right\}+\left(\frac{\partial u}{\partial y}+\frac{\partial v}{\partial x}\right)^{2}\right]
$$

where the first term of this equation represents the entropy generation due to heat transfer, while the second term is the entropy generation due to fluid friction.

\section{Model Validation}

In order to identify the precision of the heat transfer results, the numerical method is evaluated by comparing with the results available in the literature. Here a modified geometry is considered to compare the present numerical model with Nayak et al. [26]. The modified geometry is similar to Figure 1 without the roughness elements and all the boundary conditions are identical to Figure 1. Here mixed convection of $\mathrm{Cu}$-water nanofluid utilizing 5\% volume fractions of $\mathrm{Cu}$-nanoparticles at $\mathrm{Re}=100$ and $\mathrm{Gr}=10^{3}$ is simulated and compared with Nayak et al. [26]. The properties of $\mathrm{Cu}$-water nanofluids are available in Ref. [26]. A comparison between the present prediction of the local Nusselt number $\left(\mathrm{Nu}_{H}\right)$ on the bottom wall and the data reported by Nayak et al. [26] is shown in Figure 2. It is observed that the local Nusselt number on the bottom wall obtained from present numerical code compared well with Nayak et al. [26].

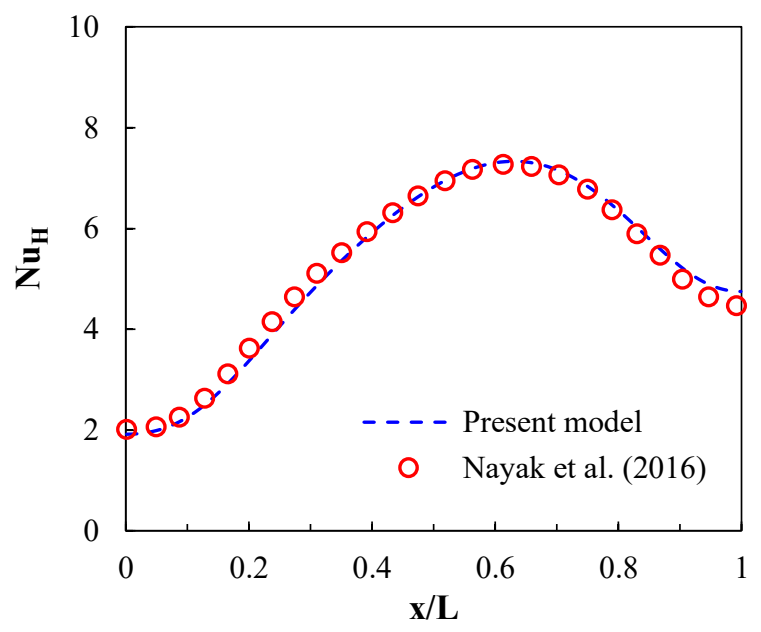

FIGURE 2. A comparison of local Nusselt number distribution along the bottom wall of a square cavity with the results available in the literature [26].

\section{RESULTS AND DISCUSSIONS}

In this section, the numerical results of mixed convection heat transfer and entropy generation for $\mathrm{Al}_{2} \mathrm{O}_{3}$-water nanofluids inside the rough cavity are presented. A set of graphs, thermal contours, and streamlines are shown to illustrate and explain the relationships between different parameters: Reynolds number (Re), scaled amplitude $(A)$, and scaled number of roughness elements $(N)$. The effects of Reynolds numbers on the heat transfer between the roughness elements and nanofluid are demonstrated in Figure 3 in terms of the average Nusselt number $\left(\mathrm{Nu}_{\text {avg }}\right)$. This figure presents $\mathrm{Nu}_{\text {avg }}$ for two scaled number of roughness elements and two scaled amplitudes as a function of Reynolds number. The results shown are for $1 \% \mathrm{Al}_{2} \mathrm{O}_{3}$-water nanofluid at Rayleigh number (Ra) of $10^{5}$. According to Figure 3, increase in $\mathrm{Re}$ number generates a linear increment in $\mathrm{Nu}_{\text {avg }}$ for all cases with different amplitude and number of roughness elements. Increase in Re indicates the increase of lid velocity, which enhances the forced convection effect due to the greater impact of the inertial force of nanoparticles. Hence, a higher lid velocity 
provides a better mixing and a higher mixed convective heat transfer inside the cavity. This could be further explained by comparing the isothermal and streamline plots for low and high Reynolds numbers.
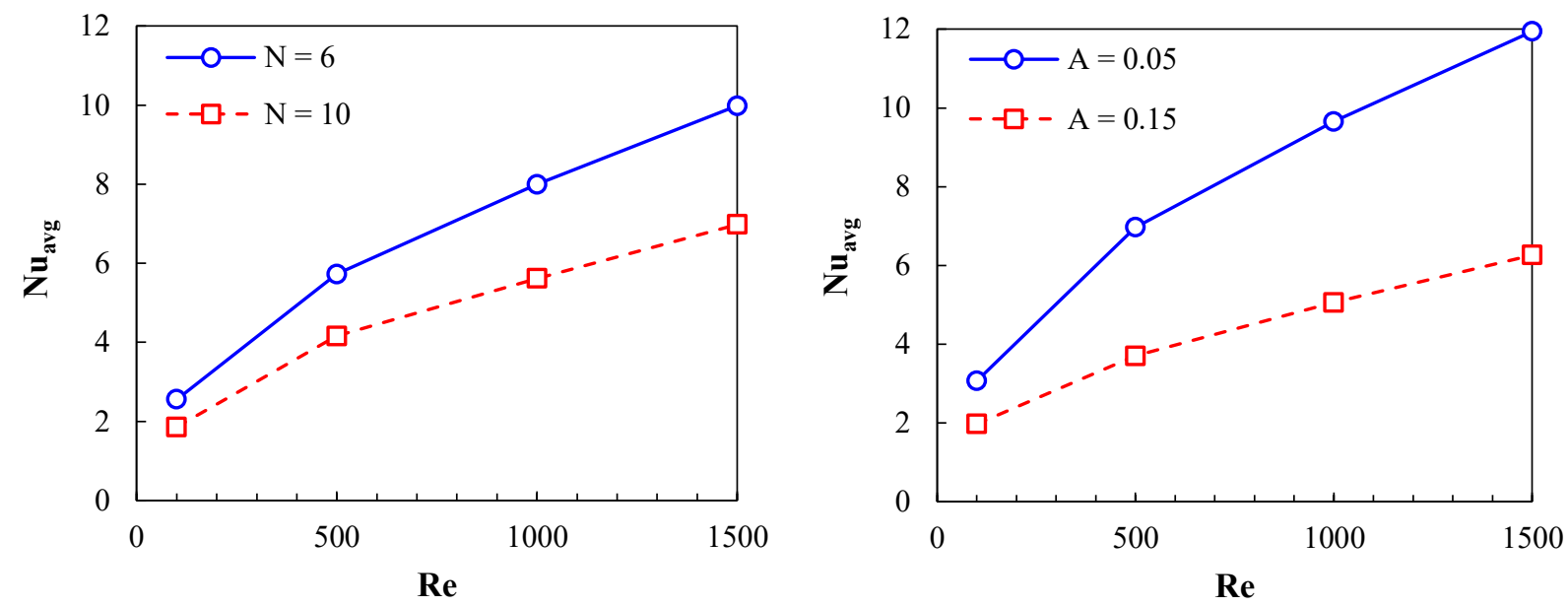

FIGURE 3. Effects of Reynolds number on the average Nusselt number $\left(\mathrm{Nu}_{\mathrm{avg}}\right)$ for two values of the scaled number of roughness elements $(N)$ and scaled amplitudes $(A)$ at $\varphi=1 \%$ and $\mathrm{Ra}=10^{5}$.

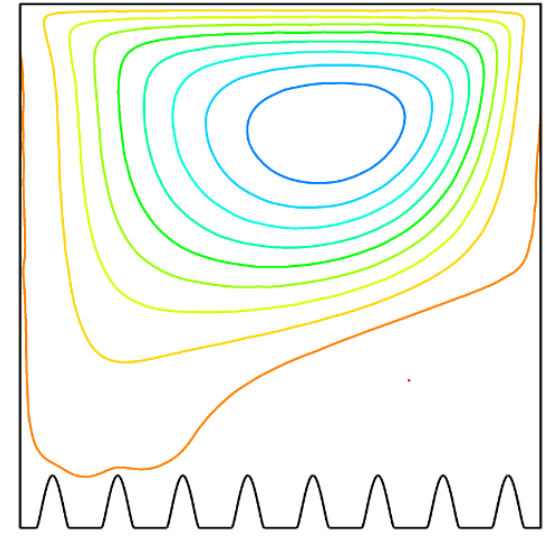

(a) $\operatorname{Re}=100$

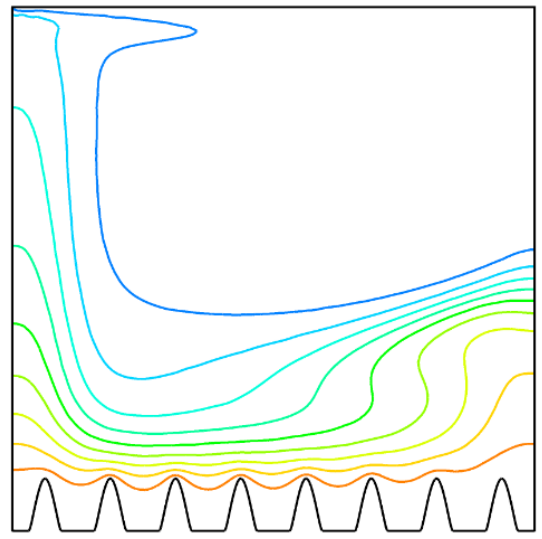

(c) $\operatorname{Re}=100$

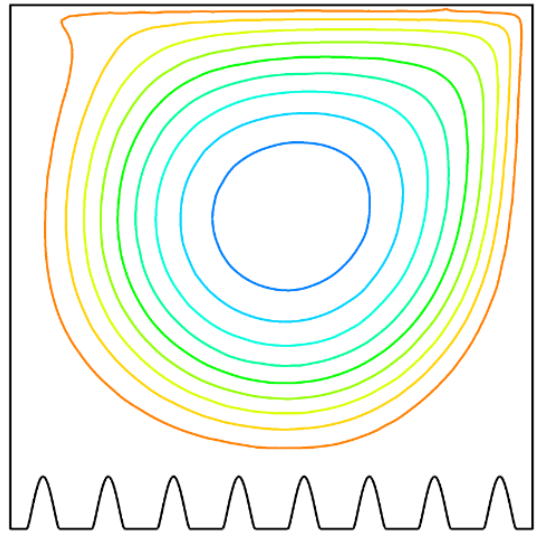

(b) $\operatorname{Re}=1000$

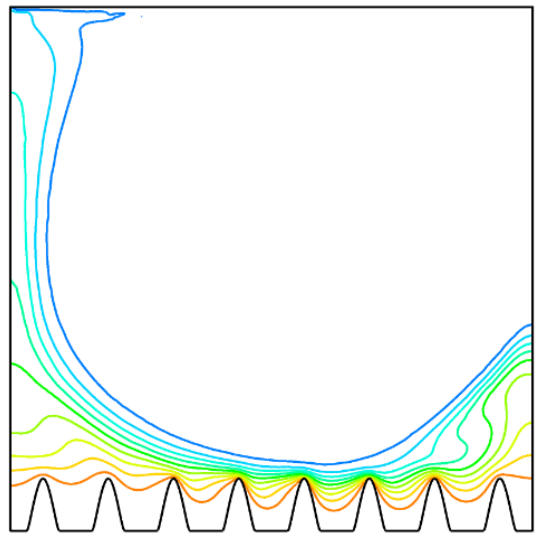

(d) $\operatorname{Re}=1000$

FIGURE 4. Streamline (top) and isothermal (bottom) plots for $\operatorname{Re}=100$ and 1000 at $\varphi=1 \%, \operatorname{Ra}=10^{5}, N=8$ and $A=0.10$. 
Figure 4 shows the isothermal and streamline plots for $\operatorname{Re}=100$ and 1000 at $\varphi=1 \%, \operatorname{Ra}=10^{5}, N=8$ and $A=$ 0.10 . These isothermal and streamline plots show that at low Reynolds number, the buoyancy force dominates the flow and the inertial force has negligible effect. Thus, the moving lid only affects part of the cavity and the diffusion is the primary mechanism of thermal transport from the bottom wall to the surrounding nanofluid. Hence, the values of average Nusselt number are smaller. At higher Reynolds number $(\operatorname{Re}=1000)$, the inertial force dominates the flow inside the cavity (Fig. 4b) and provides a better mixing between the cold and hot nanofluids. The corresponding isothermal plot shows that the convection is the primary mode of heat transfer between the bottom rough surface and the surrounding nanofluid. Although the higher Reynolds number provides a higher $\mathrm{Nu}_{\text {avg, }}$, the addition of surface roughness at the bottom wall seems to adversely affect the heat transfer. As observed in Figure 3, a higher number of the roughness elements shows lower $\mathrm{Nu}_{\text {avg }}$ compared with the lower number of roughness elements. The same scenario is observed when we change the amplitude of the roughness elements. Higher amplitude of the roughness element gives lower $\mathrm{Nu}_{\text {avg. }}$. This trend indicates the convective heat transfer reduces with the roughness and the conduction between the bottom wall and nanofluid increases.

Figure 5 depicts the effects of the scaled number of roughness elements and scaled amplitude on the total entropy generation $\left(\mathrm{S}_{\mathrm{gen}}\right)$ and the average Bejan number $\left(\mathrm{Be}_{\mathrm{avg}}\right)$. Here the average Bejan number is estimated by integrating the local Bejan number over the entire domain, where the local Bejan number is defined as the ratio between heat transfer irreversibility and the total entropy generation. It is observed that there is an increasing trend in the total entropy generation with the increase of amplitude. When amplitude changes from 0.05 to 0.15 in the case of $N=6$, it resulted in enhancement of $9.8 \%$ in total entropy generation. On the other hand, an increase in the number of roughness elements reduces the total entropy generation. Roughness element of 10 produces a decrement of less than $1 \%$ in total entropy generation compared to roughness elements of 6 at $A=0.05$. The increase in the number and amplitude of roughness elements augments the average Bejan number within the cavity. At $N=6$, the increment of $8.5 \%$ in $\mathrm{Be}_{\text {avg }}$ is observed when $A$ increases from 0.05 to 0.15 . Meanwhile, the increment in $\mathrm{Be}_{\text {avg }}$ is only $3.4 \%$ with the addition of the roughness element number from 6 to 10 at $A=0.05$. It is worth noting that varying amplitude shows a greater effect than the number of roughness elements in the enhancement of heat transfer rate, total entropy generation, and the average Bejan number. Figure 5 further shows that the increase of heat transfer irreversibility due to the roughness amplitude is higher than the increase of fluid friction irreversibility.
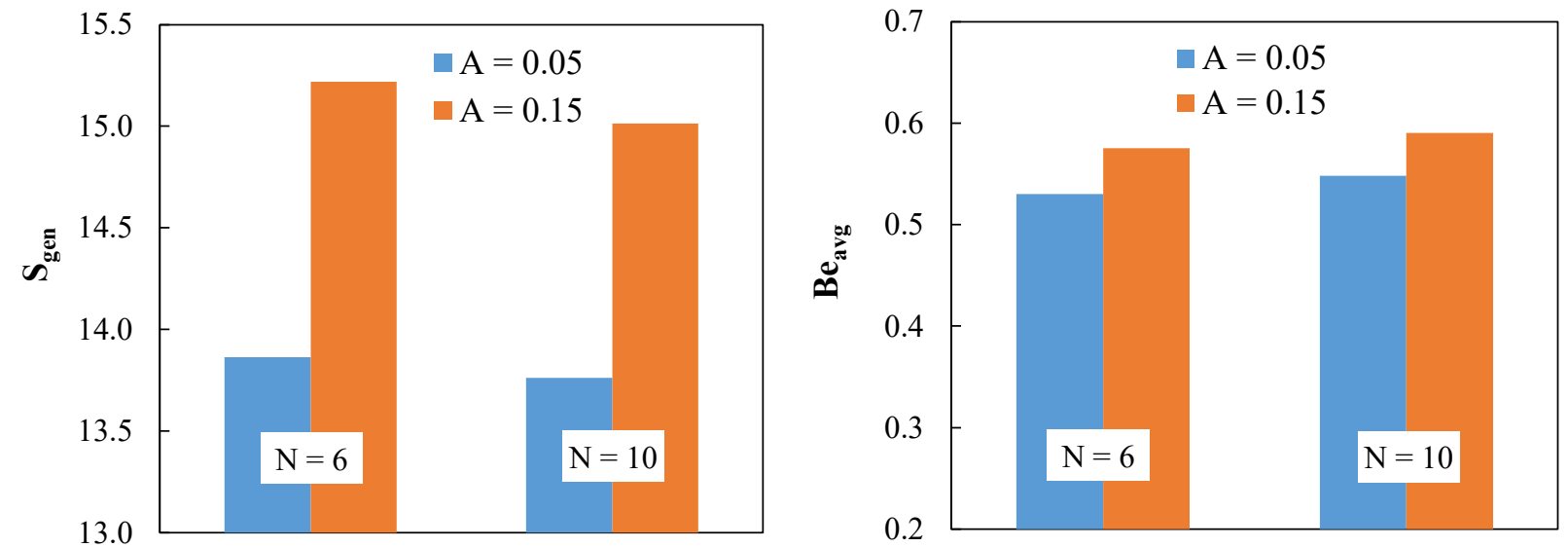

FIGURE 5. Effects of scaled amplitude $(A)$ and scaled number of roughness elements $(N)$ on the entropy generation (Sgen) and Bejan number (Be avg).

\section{CONCLUSIONS}

The present numerical study investigated the mixed convection and entropy generation of $\mathrm{Al}_{2} \mathrm{O}_{3}$-water nanofluids inside a rough cavity with a horizontal wavy wall, represented as a rough wall, to provide insight into the enhancement of heat transfer through geometry and medium optimization. It has been observed that higher Reynolds number provides better mixing of nanofluid and hence provides a higher heat transfer. Conversely, the addition of 
roughness elements reduces the average Nusselt number. Thus, the convective heat transfer between the heated wall and the surrounding nanofluid is lower. Despite the relative strength of convective to conduction heat-transfer reduces due to the roughness elements, it provides a higher conduction heat transfer from the heated surface due to the higher active surface area. It is further concluded that amplitude has a greater effect than the number of roughness elements in the enhancement of heat transfer rate, total entropy generation, and the average Bejan number.

\section{REFERENCES}

1. S. Ostrach, Adv. Heat Transfer 8, 161-227 (1972).

2. Y. Jaluria and S. K. Gupta, Int. J. Energ. Res. 7, 201-210 (1983).

3. D. Poulikakos and A. Bejan, J. Heat Transfer 105, 652-655 (1983).

4. E. Papanicolaou and Y. Jaluria, Numer. Heat Tr. A-Appl. 18, 427-461 (1990).

5. M. Peric, Numer. Heat Tr. A-Appl. 24, 213-219 (1993).

6. P. K. Das and S. Mahmud, J. Therm. Sci. 9, 135-140 (2000).

7. S. Mahmud, P. K. Das and N. Hyder, Int. Commun. Heat Mass 29, 993-1003 (2002).

8. S. Mahmud, P. K. Das, N. Hyder and A. K. M. S. Islam, Int. J. Therm. Sci. 41, 440-446 (2002).

9. S. H. Tasnim, S. Mahmud and P. K. Das, Int. J. Numer. Methods Heat Fluid Flow 12, 855-869 (2002).

10. P. K. Das and S. Mahmud, Int. J. Therm. Sci. 42, 397-406 (2003).

11. P. K. Das, S. Mahmud, S. H. Tasnim and A. K. M. S. Islam, Int. J. Numer. Methods Heat Fluid Flow 13, 1097-1122 (2003).

12. J. Rostami, Heat Mass Transfer 44, 1079-1087 (2008).

13. M. Yousaf and S. Usman, Int. J. Heat Mass Transfer 90, 180-190 (2015).

14. T. Basak, S. Roy, P. K. Sharma and I. Pop, Int. J. Therm. Sci. 48, 891-912 (2009).

15. J. A. Eastman, U. S. Choi, S. Li, L. J. Thompson and S. Lee, Mater. Res. Soc. Symp. P. 457, 3-11 (1997).

16. J. Buongiorno, J. Heat Transfer 128, 240-250 (2006).

17. J. Buongiorno, D. C. Venerus, N. Prabhat, T. Mckrell, J. Townsend, R. Christianson, Y. V. Tolmachev, P. Keblinski, L. W. Hu, J. L. Alvarado, I. C. Bang, S. W. Bishnoi, M. Bonetti, F. Botz, A. Cecere, Y. Chang, G. Chen, H. S. Chen, S. J. Chung, M. K. Chyu, S. K. Das, R. Di Paola, Y. L. Ding, F. Dubois, G. Dzido, J. Eapen, W. Escher, D. Funfschilling, Q. Galand, J. W. Gao, P. E. Gharagozloo, K. E. Goodson, J. G. Gutierrez, H. P. Hong, M. Horton, K. S. Hwang, C. S. Iorio, S. P. Jang, A. B. Jarzebski, Y. R. Jiang, L. W. Jin, S. Kabelac, A. Kamath, M. A. Kedzierski, L. G. Kieng, C. Kim, J. H. Kim, S. Kim, S. H. Lee, K. C. Leong, I. Manna, B. Michel, R. Ni, H. E. Patel, J. Philip, D. Poulikakos, C. Reynaud, R. Savino, P. K. Singh, P. X. Song, T. Sundararajan, E. Timofeeva, T. Tritcak, A. N. Turanov, S. Van Vaerenbergh, D. S. Wen, S. Witharana, C. Yang, W. H. Yeh, X. Z. Zhao and S. Q. Zhou, J. Appl. Phys. 106, 094312-1094312-14 (2009).

18. R. Cong, X. Zhou, B. D. S. Machado and P. K. Das, AIP Conference Proceedings 1754, 050017 (2016).

19. J. C. Maxwell-Garnett, Philos. Trans. Roy. Soc. London Ser. A. 203, 385-420 (1904).

20. H. C. Brinkman, J. Chem. Phys. 20, 571-581 (1952).

21. P. K. Das, X. Li and Z. S. Liu, Appl. Energ. 87, 2785-2796 (2010).

22. P. K. Das, X. Li, Z. Xie and Z. S. Liu, Int. J. Energ. Res. 35, 1325-1339 (2011).

23. P. K. Das, A. Z. Weber, G. Bender, A. Manak, D. Bittinat, A. M. Herring and M. Ulsh, J. Power Sources 261, 401-411 (2014).

24. L. Xing, P. K. Das, X. G. Song, M. Mamlouk and K. Scott, Appl. Energ. 138, 242-257 (2015).

25. A. Bejan, J. Appl. Phys. 79, 1191-1218 (1996).

26. R. K. Nayak, S. Bhattacharyya and I. Pop, J. Heat Transfer 138, 012503-11 (2016). 